\title{
Diffusive Transfer During Filtration Drying of Sunflower Stalks
}

\author{
Diana Kindzera ${ }^{1}$, Volodymyr Atamanyuk ${ }^{2}$, Roman Hosovkyi $^{3}$
}

1. Institute of Chemistry and Chemical Technology, Lviv Polytechnic National University, UKRAINE, Lviv, S. Bandery street 12, E-mail: kindzera74@ukr.net

2. Institute of Chemistry and Chemical Technology, Lviv Polytechnic National University, UKRAINE, Lviv, S. Bandery street 12, E-mail: atamanyuk@ukr.net

3. Institute of Chemistry and Chemical Technology, Lviv Polytechnic National University, UKRAINE, Lviv, S. Bandery street 12, E-mail: gosovskiy_roman@meta.ua

\begin{abstract}
Filtration method for drying rough-stalked agricultural wastes that can reduce power inputs of solid biofuel production has been studied. Diffusive mass transfer has been studied during drying of grinded sunflower stalks to produce fuel briquettes. The temperature effect on effective diffusion coefficient has been examined.
\end{abstract}

Keywords: rough-stalked agricultural wastes, grinded sunflower stalks, diffusive mass transfer, filtration drying, prism-shaped particles, effective diffusion coefficient.

\section{Introduction}

The demand for alternative energy sources in Ukraine increases with rising fossil fuel prices. The country's potential capacity from biomass resources is great. Manufacturing of fuels from plant materials is a prospective direction for Ukraine. Lignocellulosic agricultural wastes are highly abundant in nature. Rough-stalked agricultural wastes are a great part of biomass resources. Sunflowers are already used for oil production, but they can be used as bio-energy plants. They grow as tall as 3-4 meters, that's why there are significant amounts of cellulosic biomass which can be converted into solid biofuel with high calorific value. Lignocellulosic material from agro-industrial wastes is a combination of cellulose, hemicellulose and lignin. The stalk composition (\%) is: cellulose - 41.8; hemicellulose - 21.3; lignin - 20.1 The high concentration of above-mentioned compounds defines highcalorific power of biofuel made from plant raw material. The technology of solid fuel production from this type of material provides stages of preliminary grinding and drying to humidity of 4-12\% favorable for sustainable briquetting and quality characteristics of received briquettes.

As a result of stalks grinding, the particles with fibrous structure are formed. The particles have prism shape with averaged size of $1.37 \times 1.91 \times 7.14 \mathrm{~mm}$. The initial average moisture content of the investigated sunflower stalks is $60 \%$. The share of costs for drying is significant in the manufacturing cost of the fuel because modern dryers used now to produce solid biofuels are energy intensive, large and require the installation of treatment equipment. All these facts correspondingly increase the cost of the finished product. We propose the filtration method that can reduce power inputs of solid biofuel production. Recent studies have demonstrated that filtration dryers are energy-efficient and environmentally friendly. Filtration drying of dispersed materials, in particular grinded rough-stalked matter, is a complex process involving mass and heat transfer. During filtration drying the moisture transfer is defined by regularities of both external and pore diffusion.

\section{The aim of the work}

The aim of the work is to study the kinetics and the diffusion processes occurred during filtration drying of grinded sunflower stalks. 


\section{Experimental study and its analysis}

The experiments were carried out at the laboratory plant. To study the diffusion processes occurred during filtration drying of grinded sunflower stalks the layer with the height $\mathrm{H}=40 \mathrm{R}$ was formed ( $\mathrm{R}$ - the defining size of prism-shaped particle). A container with a sample was placed into a drying installation. Heat agent with the temperatures of 293, 316, 333, 353 and $373 \mathrm{~K}$ was filtered through the sample layer. Heat agent flow rate was constant. The experiments were carried out till the material weight became constant. The temperature was controlled by RT-0102 thermoregulator), the sample weight was measured using Axis AD3000 electronic scales.

We studied the kinetic peculiarities of grinded sunflower stalks filtration drying at different temperatures of the heat agent.

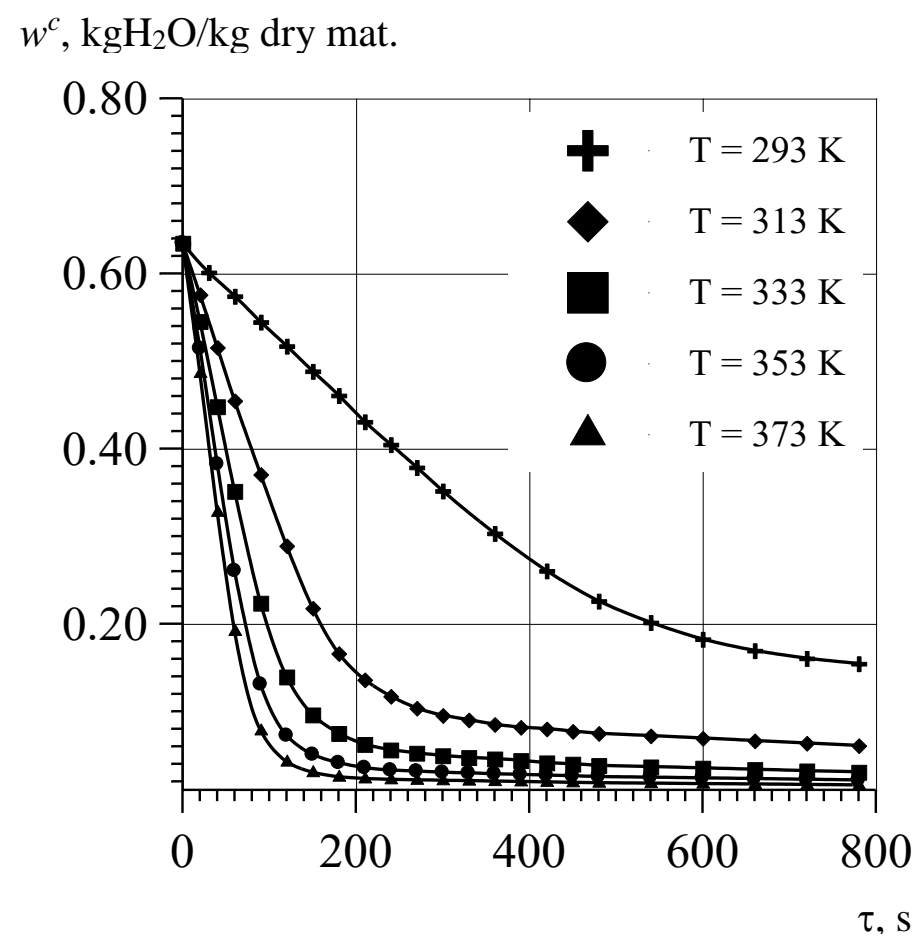

Fig. 1. Kinetics of grinded sunflower stalks drying at different temperatures of heat agent

$$
(\mathrm{H}=0.06 \mathrm{~m} ; \square 0=1.71 \mathrm{~m} / \mathrm{s}) \text {. }
$$

The upper limit is such temperature, under which spontaneous ignition does not occur. The experimental results are represented in Fig. 1. The kinetic curves are characterized by long period of partial saturation of the heat agent by moisture. This fact indicates the proceeding of pore-diffusion processes in the material particles which define the time of filtration drying. Recent studies have demonstrated that the increase in heat agent temperature intensifies the drying process. The values of final moisture content (wfc) achieved at process time of $600 \mathrm{~s}$ are given in Table 1.

Table 1

Moisture content of grinded sunflower stalks at drying time of $600 \mathrm{~s}$

\begin{tabular}{|c|c|c|c|c|c|}
\hline $\mathrm{T}, \mathrm{K}$ & 293 & 313 & 333 & 353 & 373 \\
\hline $\begin{array}{c}\mathrm{W}_{\mathrm{f}}^{\mathrm{c}}, \\
\mathrm{kgH}_{2} \mathrm{O} / \mathrm{kg} \text { dry mat. }\end{array}$ & 0.183 & 0.071 & 0.035 & 0.024 & 0.017 \\
\hline
\end{tabular}

The temperature effect on effective diffusion coefficient has been examined. The values of Dw* are represented in Table 2. 
Dependence of effective diffusion coefficient on the heat agent temperature

\begin{tabular}{|c|c|c|c|c|c|}
\hline $\mathrm{T}, \mathrm{K}$ & 293 & 316 & 333 & 353 & 373 \\
\hline $\mathrm{D}_{\mathrm{w}}{ }^{*} \cdot 10^{8}, \mathrm{~m}^{2} / \mathrm{s}$ & 1.056 & 4.156 & 6.749 & 9.291 & 13.474 \\
\hline
\end{tabular}

Overall, the results show that the increase of heat agent temperature increases the temperature inside the particles and saturation vapor pressure over the liquid surface and thus intensifies the diffusion processes. The graphic dependence $\mathrm{Dw}^{*}=\mathrm{f}(\tau)$ is plotted on the basis of results from Table 2 (Fig. 2).

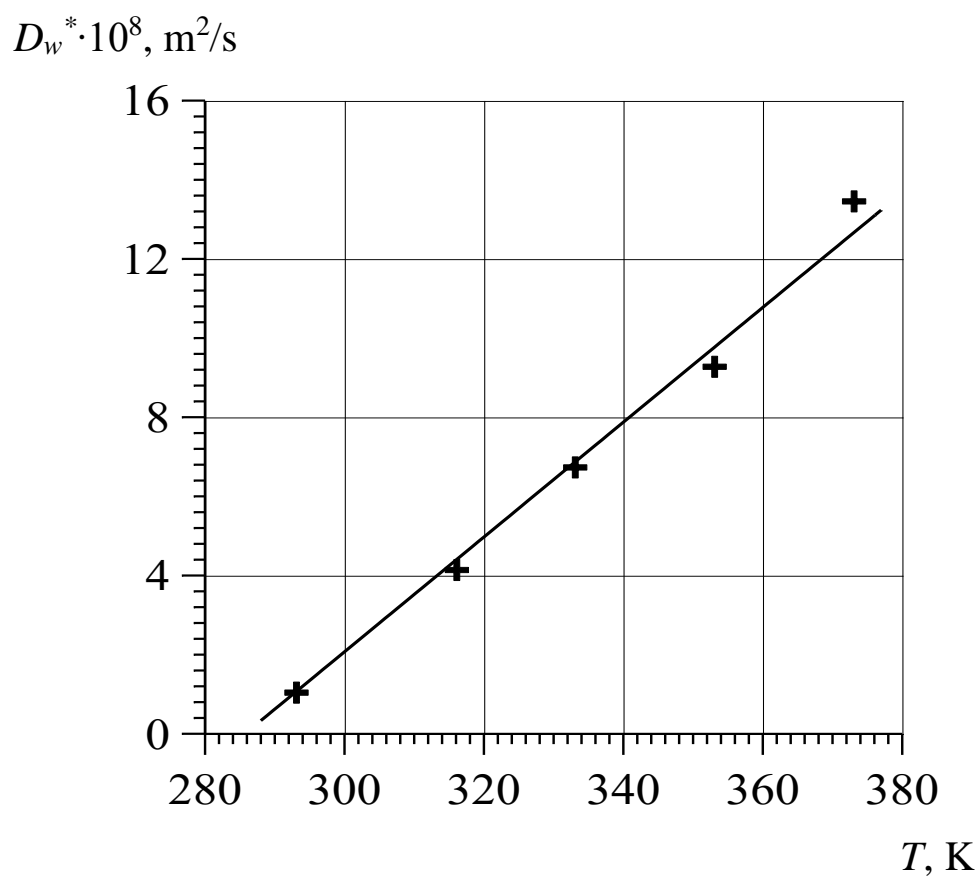

Fig. 2. Effective diffusion coefficient $\mathrm{Dw}^{*}$ vs. the heat agent temperature

\section{Conclusions}

As the result of these research studies, the estimated dependence of the effective diffusion coefficient on the heat agent temperature is approximated by equation:

$$
D_{w}^{t}=D_{w}^{293}+1.45 \cdot 10^{-9}(T-293)
$$

The deduced equation allows to calculate theoretically the effective diffusion coefficient for the grinded sunflower stalks within temperature range of 293-373 K.

\section{References}

[1] Kindzera D., Atamanyuk V. and Hosovsky R.: Visnyk Odesa Nats. Acad. 2015, 42, 194.

[2] Atamanyuk V. and Gumnytskyi Ya.: Naukovi Osnovy Filtracijnogo Sushinnya Dispersnykh Materialiv. Vyd-vo Lviv.Polytech., Lviv 2013.

[3] Barna I., Gumnytskyi Y. and Atamanyuk V.: Chem. Chem. Technol., 2013, 7, 129.

[4] Mykychak B., Biley P. and Kindzera D.: Chem. Chem. Technol., 2013, 7, 191.

[5] Snezhkin Yu., Korinchuk D., Vorobiov L. and Kharin O.: Prom. Teplotechn., 2006, 28, 41.

[6] Lykov A.: Teoriya Teploprovodnosti. Vysshaya Shkola, Moskva 1967. 